\title{
Development of a Complex Catalytic Conversion System for Internal Combustion Engines Fueled with Natural Gas
}

\author{
Vladislav Anatolievich Luksho ${ }^{1}$, Andrey Victorovich Kozlov ${ }^{1}$, Vladimir Ivanovich Panchishny ${ }^{1} \&$ Alexey \\ Stanislavovich Terenchenko ${ }^{1}$ \\ ${ }^{1}$ Federal State Unitary Enterprise Central Scientific Research Automobile and Automotive Institute "NAMI" \\ (FSUE «NAMI»), National Research Nuclear University MEPhI (Moscow Engineering Physics Institute), Russia \\ Correspondence: Vladislav Anatolievich Luksho, Federal State Unitary Enterprise Central Scientific Research \\ Automobile and Automotive Institute "NAMI" (FSUE «NAMI»), National Research Nuclear University MEPhI \\ (Moscow Engineering Physics Institute), Russia.
}

Received: January 15, 2015

Accepted: February 3, $2015 \quad$ Online Published: July 30, 2015

doi:10.5539/mas.v9n8p237

URL: http://dx.doi.org/10.5539/mas.v9n8p237

\begin{abstract}
The paper related to developing of a new gas engines with high energy efficiency and meeting future emission standards. It is necessary to develop complex exhaust gas aftertreatment systems to treat the toxic components efficiently when the engine runs on stoichiometric and lean mixtures. It is proposed to use new combination of three-way catalyst for working on stoichiometric mixtures and a selective catalytic reduction system for $\mathrm{NO}_{\mathrm{x}}$ aftertreatment on lean mixtures. Experimental studies have shown that efficient (over 90\%) conversion of gas engine exhaust components takes place in the range of air excess ratio from 0.99 to 1.01 . Theoretical studies have shown that the highest efficiency of nitrogen oxides reduction is achieved in the temperature range of $400 \ldots 500^{\circ} \mathrm{C}$ and reaches over $97 \%$.
\end{abstract}

Keywords: natural gas, internal combustion engines, aftertreatment system, nitrogen oxides, three-way catalyst, selective catalytic reduction

\section{Introduction}

Depletion of oil reserves, pollution of air with harmful substances and global warming make it necessary to look for solutions to these global problems. One of the most efficient and comprehensive ways to solve them is to replace petroleum-based fuels for internal combustion engines by alternative fuels. The most promising approach, according to many scientists and experts, is the use of natural gas as fuel both in compressed and liquefied form (Luksho, 2014; Bakhmutov and Karpukhin 2012).

The main advantage of natural gas is its better environmental footprint. The exhaust gases of natural gas powered engines contain less harmful substances, compared with petrol and diesel engines. They produce less carbon monoxide by $50-70 \%$, less non-methane organic gases and nitrogen oxides by $70-80 \%$ and less carbon dioxide by 15-20\% (Luksho et al., 2011; Luksho, 2010).

There are certain other advantages of using natural gas as motor fuel. In particular, after desulfurization methane contains almost no sulfur, whose combustion products can be harmful to the health of people and other living organisms, acidify soil and water, destroy the monuments, building facades, etc. Therefore, a comprehensive assessment of the most harmful components of exhaust gases, created by engines running on natural gas, shows that such engines are significantly less dangerous than gasoline or diesel ones.

However, transition to gas fuel does not fully solve environmental problems exposed by tightened environmental standards. These problems are mainly related to two components, namely methane and nitrogen oxides, although the transition to advanced (Euro 5 and Euro 6) standards can make it difficult to avoid violating the maximum levels of other regulated substances.

In particular, when converting a diesel engine to methane fuel, scientists at NAMI and other researchers reported a very high level of methane emissions, which is several times greater than current standards. Therefore, even Euro-3 required the use of catalytic converters with high content of precious metals, with significantly (three or more times) greater concentration thereof than in the conventional oxidation converters for gasoline and diesel engines. 
Transition from Euro-4 to Euro-6 implies stricter requirements for emissions of hydrocarbons, including 2.2 - 3.4 times stricter requirements for methane, depending on the type of engine, regulated exhaust component and normalized test cycle (Table 1). For example, for $\mathrm{CH}_{4}$ it corresponds to emission reduction from $1.1 \mathrm{~g} / \mathrm{kWh}$ (ETC - cycle) to $0.5 \mathrm{~g} / \mathrm{kWh}$ during transition from Euro-4 to Euro-6. The task of satisfaction to the standards for nitrogen oxides is even more difficult. In accordance with the norms for complying with future requirements quoted in the table 1, the toxicity levels caused by nitrogen oxides should be reduced by more than 8 times during transition from Euro-4 to Euro-6. Standard values for other toxic components are significantly reduced too. It is necessary to take into account the effects of inevitable aging, which affects components of the system. As a result, the initial levels of treatment should be set with a significant (20-30\%) margin.

Table 1. Emission standards for toxic emissions

\begin{tabular}{llllll}
\hline & Regulatory & \multicolumn{4}{c}{ ETC cycle, $\mathrm{g} / \mathrm{kWh}$} \\
& $\mathrm{CO}$ & $\mathrm{NMHC}$ & $\mathrm{CH}_{4}{ }^{\mathrm{a}}$ & $\mathrm{NO}_{\mathrm{x}}$ & $\mathrm{PM}$ \\
\hline Euro-4 & 4.0 & 0.55 & 1.1 & 3.5 & 0.03 \\
Euro-5 & 4.0 & 0.55 & 1.1 & 2.0 & 0.03 \\
Euro-6 & 4.0 & 0.16 & 0.5 & 0.4 & 0.01 \\
\hline
\end{tabular}

a - only for natural gas fueled engines.

One of important problems in converting diesel engines to natural gas is an efficiency drop, caused, in particular, by lower compression ratio. Studies conducted at NAMI have shown possibility of substantial (10...15\%) improvement of fuel economy at partial load conditions when running with stoichiometric mixtures, using the Miller cycle and maintaining the same geometric compression ratio as in the diesel prototype engine.

Further increase of the gas engine's efficiency is possible through leaning of the combustion mixture at partial loads, however, it creates a problem of increased NOx emissions, because three-way catalyst is not efficient for $\mathrm{NO}_{\mathrm{x}}$ at lean-burn operation.

Thus, to develop new gas engines with high energy efficiency and meeting future emission standards, it is necessary to develop complex exhaust gas aftertreatment systems to treat the toxic components efficiently when the engine runs on stoichiometric and lean mixtures. This paper discusses issues related to creation of such complex systems.

\section{Complex Catalytic Conversion System}

Meeting the future requirements on the toxic emissions of a natural gas engine is possible by using an integrated system of catalytic conversion, able to work efficiently with different air-fuel ratios.

Table 2 shows the influence of air excess ratio $\lambda$ in the mixture on the choice of technologies that may be used for efficient treatment of exhaust gases. Engine operation mode and air excess ratio $\lambda$ determine the exhaust composition of the natural gas fueled ICE's and, consequently, the type or set of catalysts, which can be used in the process of aftertreatment.

The exhaust gas treatment technologies, used for ICEs running on natural gas, may be divided into oxidation, reduction, oxidation-reduction and complex conversion systems, depending on the concentrations of toxic components, oxygen and temperature.

In the reviewed version of a gas engine operating with both stoichiometric and lean mixtures a complex system of catalytic conversion is necessary.

The system shall consist of a three-way catalyst to ensure treatment of gases when the engine runs with stoichiometric mixtures and a selective catalytic reduction (SCR) system of nitrogen oxides for lean-burn operation. A scheme of an integrated system is shown in Figure 1.

Table 2. Effect of air excess ratio $(\lambda)$ on the choice of exhaust gas aftertreatment technology

\begin{tabular}{|c|c|c|c|}
\hline$\lambda$ & Process type & Toxic components & Main reactions \\
\hline$\lambda<1$ ("rich" mixture) & oxidation/reduction & $\mathrm{NO}_{\mathrm{x}}, \mathrm{CO}, \mathrm{HC}$ & $\begin{array}{l}2 \mathrm{CO}+2 \mathrm{NO} \rightarrow 2 \mathrm{CO}_{2}+\mathrm{N}_{2} \\
\mathrm{HC}+\mathrm{NO} \rightarrow \mathrm{CO}_{2}+\mathrm{H}_{2} \mathrm{O}+\mathrm{N}_{2} \\
2 \mathrm{CO}+\mathrm{O}_{2} \rightarrow 2 \mathrm{CO}_{2} \\
\mathrm{HC}+\mathrm{O}_{2} \rightarrow \mathrm{CO}_{2}+\mathrm{H}_{2} \mathrm{O}\end{array}$ \\
\hline
\end{tabular}




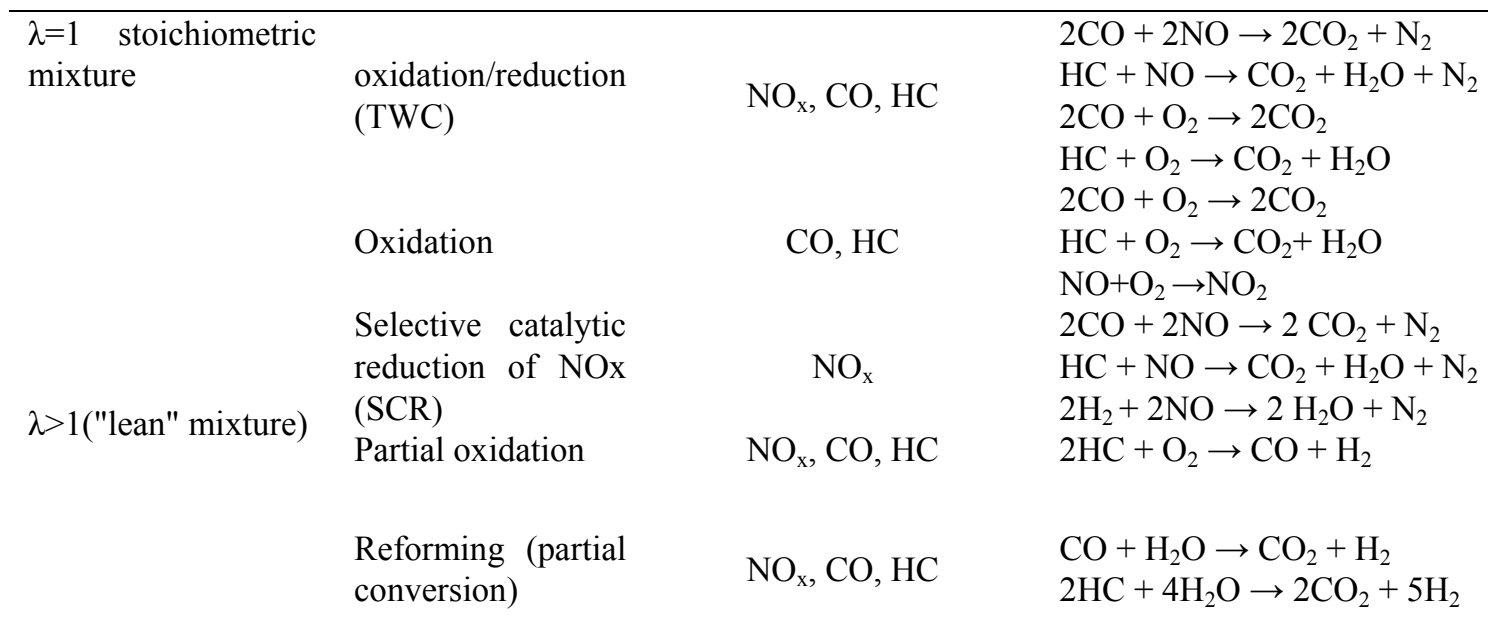

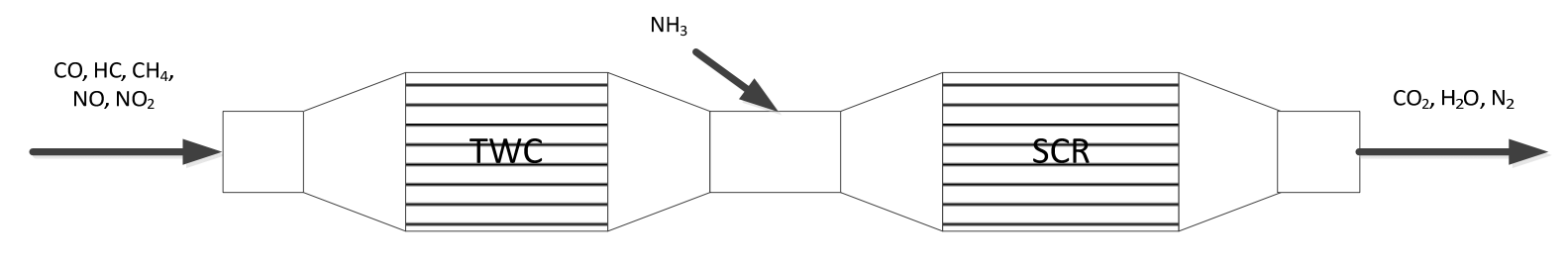

Figure 1. An integrated system of exhaust gas aftertreatment

The choice of catalysts is the question of utmost importance when creating a catalytic conversion system. The main parameters needed when choosing a catalyst include clear definition of the composition, temperature and flow rate of the exhaust gas, which, in turn, are determined by design choices, engine operation mode, fuel and air supply systems of the engine. The following subsections present the results of studies and analysis of the most efficient catalytic coatings for use in a complex catalytic conversion system of a gas engine. Three-way catalyst was experimentally tested on motor test bench. Selective catalytic reduction system was investigated by computer simulation technique.

\section{Three-Way Catalytic Converter}

The worldwide community have accumulated a lot of experience in creation of catalysts for three-way conversion (TWC) of CO, NOx and hydrocarbons in exhaust gases. It have been established that simultaneous conversion of these components is possible only when the oxygen concentration is close to stoichiometric or lower. These conditions are successfully implemented in modern engines with electronically controlled fuel ratio. The use of TWC conversion systems for gas engines has its own peculiarities associated with the need to oxidize relatively large (compared to other hydrocarbons) amount of methane.

Methane is the most difficult compound to oxidize among light paraffins.

$$
\mathrm{CH}_{4}+2 \mathrm{O}_{2} \rightarrow \mathrm{CO}_{2}+2 \mathrm{H}_{2} \mathrm{O}, \Delta \mathrm{H}^{\mathrm{o}}{ }_{298}=805,0 \mathrm{~kJ} / \mathrm{mol} \text {. }
$$

Inactivity of methane is due to high strength and low polarity of the $\mathrm{C}-\mathrm{H}$ bond and stiffness of the tetrahedral structure, which complicates activation of the $\mathrm{CH} 4$ molecule. The energy gap of the $\mathrm{C}-\mathrm{H}$ bond in $\mathrm{CH}_{4}$ is $423,2 \times 10^{3} \mathrm{~kJ} / \mathrm{mol}, 398,0 \times 10^{3}$ in propane and $322,0 \times 10^{3}$ in propylene. Higher strength of the $\mathrm{C}-\mathrm{H}$ bond in methane complicates its combustion process and is a major cause of increased hydrocarbons emission, which is usually significantly greater than permissible level.

Therefore, to meet the requirements of modern standards for emissions of CO and hydrocarbons, a catalytic converter is required, which provides an effective afterburning of methane and other hydrocarbons at $80-90 \%$ on average at the most typical exhaust temperatures of a gas engine $\left(350-500^{\circ} \mathrm{C}\right)$.

The most efficient catalysts for complex conversion processes are Pt-Pd-Rh-on-alumina catalysts with modifying 
additives, a mixture of $\mathrm{Ce}, \mathrm{Zr}$, La oxides is successfully used. The most commonly used ratio of $\mathrm{Pt}: \mathrm{Pd}: \mathrm{Rh}$ is $1: 5: 1$ and total concentration of active ingredients is $1.4 \div 2.1$ grams per liter of catalyst. When using this catalyst for complex conversion of emissions from ICE running on natural gas, in $\lambda=1$ mode or methane oxidation $(\lambda>1)$ the concentration of Pt-Pd-Rh is increased to 4 or more grams per liter of catalyst.

NAMI conducted comparative laboratory tests of $\mathrm{Pt}, \mathrm{Pd}$, and $\mathrm{Pt}-\mathrm{Rh}$ catalysts in a bifunctional mode on gas mixture containing $\mathrm{CO}$, NO and propane or methane. Tests showed that Pt-Rh catalyst at $\lambda=1$ is active in simultaneous oxidation of $\mathrm{HC}, \mathrm{CO}$ and reduction of $\mathrm{NO}$ by $70-80 \%$ at temperatures of $300-320{ }^{\circ} \mathrm{C}$ in the presence of propane and at $380-400{ }^{\circ} \mathrm{C}$, if the mixture contains methane. The catalysts are ordered by their activity as follows: $\mathrm{Pt}-\mathrm{Rh}, \mathrm{Pt}, \mathrm{Pd}$. Increasing the concentration of active components in the catalyst from 1.2 to $2.2 \mathrm{~g} / 1$ leads to an increase in activity of the catalyst, which is especially pronounced at temperatures more than $450^{\circ} \mathrm{C}$. At $\lambda>1$ the catalysts based on platinum group metals work only in deep oxidation mode and do not initiate reduction of nitrogen oxides.

A positive effect is demonstrated by layering of active components in the catalys carrier, which allows not only to improve resistance of catalysts to poisoning, but also regulate the temperature of the three-way conversion process. The optimal choice is when the outer layer consists of palladium with stabilizing dioxide additives of, e.g. cerium, while rhodium and platinum remain in the inner layer. This arrangement makes it possible to reduce the light-off temperature of the reaction of hydrocarbons' and $\mathrm{CO}$ oxidation at the surface and considerably reduces platinum and rhodium sintering, which are protected by the upper layers of the catalyst and also increases both the role of rhodium during reduction of $\mathrm{NO}_{\mathrm{x}}$, and the ability of cerium oxide to accumulate oxygen (Gandhi et al., 2003; Kinnunen, 2011; Kašpar et al., 2003).

Oxidation of $\mathrm{CH}_{4}$ with a "rich" mixture $(\lambda=0.988 \div 0.995)$ runs easier than in bifunctional mode $(\lambda=1)$, for example, the methane conversion rate at $360^{\circ} \mathrm{C}$ with a "rich" mixture is $90 \%$ versus $65 \%$ at $\lambda=1$. The increase of $\mathrm{CH}_{4}$ contents after catalyst in the temperature range of $280-400^{\circ} \mathrm{C}$ is higher and the difference in effectiveness of the catalyst decreases as the temperatures go higher. Consequently, this catalyst is best used at $\lambda=0.988 \div 0.995$, when both $\mathrm{NO}_{\mathrm{x}}$ reduction and $\mathrm{CH}_{4}$ oxidation run at maximum rate (Wit et al., 2000; Nellen and Boulouchos, 2000; Gélin and Primet, 2002).

NAMI has conducted research of three-way catalyst's efficiency for aftertreatment of exhaust gases of a 6-cylinder gas engine running in Miller cycle. In the Miller cycle, the intake valve is left open longer than it would be in an Otto cycle engine. The engine has cylinders with bore and stroke $105 \times 128 \mathrm{~mm}$, nominal power of $180 \mathrm{~kW}$ at speed of $2300 \mathrm{RPM}$. The studies were conducted at $30 \ldots 70 \%$ of the rated load and engine speed of $1400 \ldots 1800$ RPM. Air excess ratio was changed by variation of fuel supply rate at constant throttle position and it was calculated as ratio of real air consumption to theoretically required to full combustion of expended fuel. The results of measuring concentrations of toxic components before and after the catalyst according to the excess air ratio are shown in Figure 2. 


\section{CH, NOx}

CO,

ppm

1000

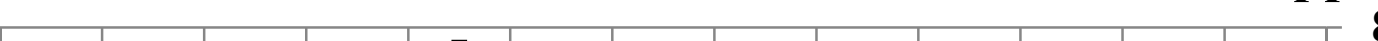

ppm

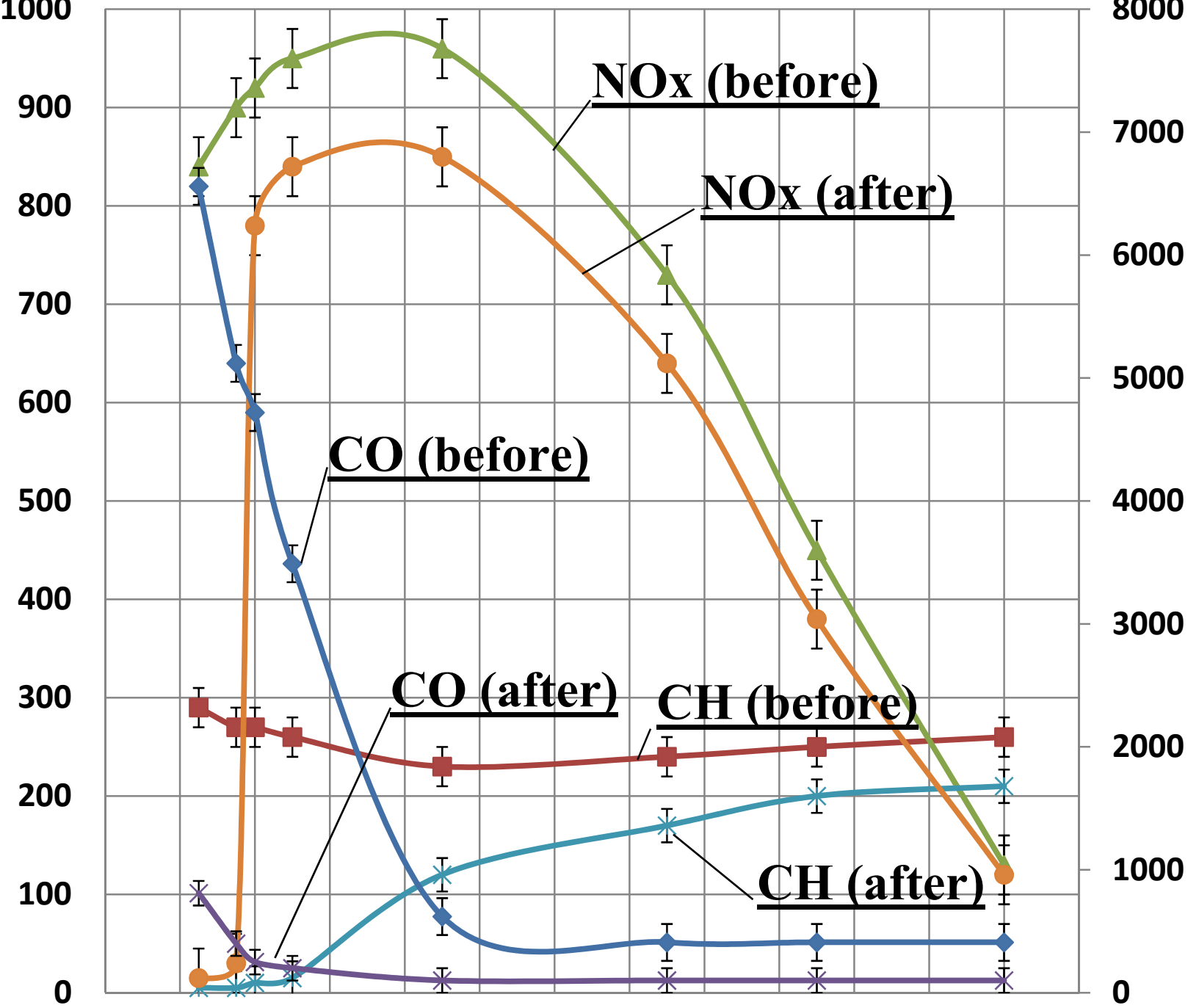

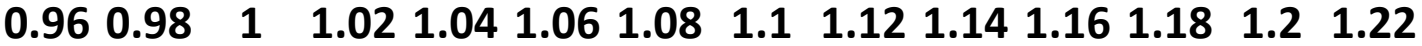 Air excess ratio}

Figure 2. Concentration of toxic components in the exhaust gases before and after catalyst depending on the air excess ratio

As the experiments showed, the highest conversion efficiency (over 90\%) for all three components was achieved in the air excess ratio range from 0.99 to 1.01 . When the mixture got leaner to $\lambda>1.09$, there was a sharp decrease in the efficiency of nitrogen oxides reduction.

Thus, it is shown that a TWC converter is a complex multifunctional system, which must have a layered structure comprising a metallic or ceramic matrix, a secondary carrier and an active phase, able to simultaneously ensure oxidation of $\mathrm{CO}, \mathrm{HC}$ and $\mathrm{NO}_{\mathrm{x}}$ reduction at oxygen concentration below or near stoichiometric in a wide range of temperatures and presence of small amounts of poisons $\left(\mathrm{SO}_{2}, \mathrm{H}_{2} \mathrm{~S}, \mathrm{P} \leq 10 \mathrm{ppm}\right)$. The active phase should include: 1 - active components (platinum group metals $\mathrm{Pt}, \mathrm{Pd}, \mathrm{Rh}$ or a mixture thereof); 2 - oxygen accumulator $\left(\mathrm{CeO}_{2}, \mathrm{ZrO}_{2}\right.$ or mixture thereof); 3 - stabilizers and a carrier (RZE, SZE or a mixture 
thereof); 4 - poison sorbing components.

\section{Selective Catalytic Reduction of Nitrogen Oxides}

In the cases, where nitrogen oxides pose the biggest problem in the overall balance of harmful engine emissions, the systems based on selective reduction of $\mathrm{NO}_{\mathrm{x}}$ become the most widely spread, and the preferred reductant is carbamide (urea). The most common way of urea application is $32.5 \%$ solution in demineralized water under a trade name "AdBlue". The use of selective reducing agents containing amino groups in its structure allows for deeper reduction of nitrogen oxides in exhaust gases. However, it creates problems of filling and carrying on-board an additional reagent, possible interactions between construction materials and amino compounds, own toxicity of ammonia in case of incomplete reaction and possibility of secondary nitrogen oxide formation during oxidation of unreacted ammonia in the catalyst.

Studies of the processes of nitrogen oxides reduction with hydrocarbons, in particular by gaseous methane, are presented in (Hamill et al., 2014; Jing et al., 2009), however the efficiency of such systems is not sufficient to meet Euro-6 level norms. In this regard, the use of nitrogen oxide reduction systems utilizing urea seems to be a more promising approach.

An outline of the $\mathrm{NH}_{3}$-SCR process is shown in Figure 3.

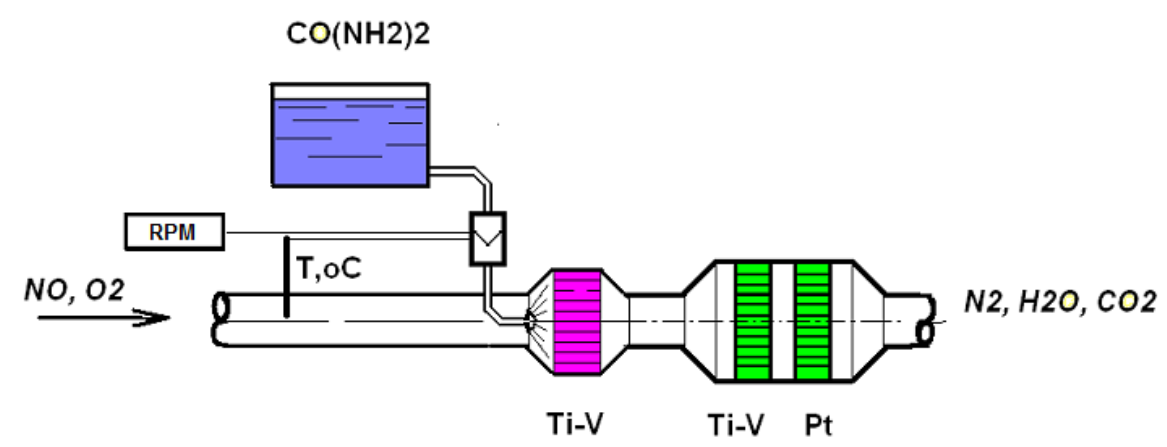

Figure 3. Scheme of the $\mathrm{NH}_{3}$-SCR process

Selective reduction of nitrogen oxides using urea as a source of ammonia is sufficiently studied and the most efficient catalysts based on titanium oxide with additives of $\mathrm{V}_{2} \mathrm{O}_{5}, \mathrm{WO}_{3}, \mathrm{MoO}_{3}, \mathrm{Fe}_{2} \mathrm{O}_{3}$, or a combination mentioned above, are identified (Caton and Siebers, 1989; Long and Yang, 1999; Komatsu et al., 1994; Gieshoff et al., 2000; Uddin et al., 1995; Koebel et al., 2001). NAMI has conducted work to create a system and a catalyst on a block metallic carrier (BMN) to implement selective reduction of $\mathrm{NO}_{\mathrm{x}}$ for a diesel engine. It has been found that the efficiency of vanadium-titanium catalysts on BMN in the reaction of nitrogen oxides reduction with ammonia in the presence of excess oxygen depends on several parameters, among which the most important are: composition, substrate structure, volume velocity, catalyst technology and exhaust gas temperature (Gieshoff et al., 2000).

It is possible that this catalytic system could also be used for an engine running on natural gas. In addition to the catalyst for selective reduction of nitrogen oxides the $\mathrm{NH}_{3}$-SCR system includes catalysts of urea hydrolysis and final reduction of, e.g. ammonia. This technology has a number of thermal limitations, because hydrolysis of urea at $\mathrm{T}>400-500^{\circ} \mathrm{C}$ may produce crystalline compounds poorly soluble in water, such as triurea and carbamyl urea, which are incapable of hydrolysis. In addition, the number of active $\mathrm{V}^{4+}$ sites at these temperatures in V-Ti composition decreases, $\mathrm{V}^{5+}$ and higher phases appear, which oxidize ammonia at the stage of $\mathrm{NO}_{\mathrm{x}}$ and nitrogen reduction, significantly reducing the catalyst's efficiency.

Therefore, the main attention, as studies show, must be focused on the method to form the active surface of the catalyst and its stabilization, i.e. the method of catalyst preparation and its operating conditions. These problems and lack of experience with NH3-SCR system in vehicles powered by natural gas, do not exclude the possibility of its modernization and future use.

Alternatives to the V-Ti composite for high-temperature $\mathrm{NO}_{\mathrm{x}}$ reduction, according to the authors (Uddin et al., 1995; Koebel et al., 2001; Weitkamp and Gläser, 2003), may be CeTi, FeTiOx, Cu/zeolite catalysts, which do not form volatile compounds and allow for the process to reduce nitrogen oxides at temperatures $50-100^{\circ} \mathrm{C}$ higher 
than vanadium contacts. In addition to $\mathrm{NH}_{3}$-SCR and hydrolysis catalysts, the system comprises an ammonia oxidation stage, because the Euro-6 standard provides for the restriction of ammonia at $10 \mathrm{ppm}$.

A number of computational studies has been performed to investigate the effectiveness of the selective catalyst in a gas engine running on lean fuel mixtures.

The computational studies used a mathematical model describing the basic chemical processes occurring in the catalytic conversion system. The reactions of nitrogen oxides reduction (Winkler et al., 2003; Wurzenberger and Wanker, 2005) and conversion of ammonia are as follows:

reduction of nitrogen oxides:

$$
4 \mathrm{NH}_{3}+4 \mathrm{NO}+\mathrm{O}_{2}=4 \mathrm{~N}_{2}+6 \mathrm{H}_{2} \mathrm{O} ;
$$

combined reduction of nitrogen oxide and dioxide:

$$
4 \mathrm{NH}_{3}+2 \mathrm{NO}+2 \mathrm{NO}_{2}=4 \mathrm{~N}_{2}+6 \mathrm{H}_{2} \mathrm{O} ;
$$

reduction of nitrogen dioxide:

$$
8 \mathrm{NH}_{3}+6 \mathrm{NO}_{2}=7 \mathrm{~N}_{2}+12 \mathrm{H}_{2} \mathrm{O}
$$

hydrolysis of isocyanic acid:

$$
\mathrm{HNCO}+\mathrm{H}_{2} \mathrm{O}=\mathrm{NH}_{3}+\mathrm{CO}_{2} ;
$$

oxidation of ammonia:

$$
4 \mathrm{NH}_{3}+3 \mathrm{O}_{2}=2 \mathrm{~N}_{2}+6 \mathrm{H}_{2} \mathrm{O} .
$$

The formulas for calculating reaction rates are as follows:

$$
\begin{aligned}
& r_{1}=K_{1} e^{\frac{-E_{1}}{R T_{s}}} C_{N O} \frac{K_{1}^{\prime} e^{\frac{-E_{1}^{\prime}}{R T_{S}}} c_{N H_{3}}}{1+K_{1}^{\prime} e^{\frac{-E_{1}^{\prime}}{R T_{S}}} c_{N H_{3}}} ; \\
& r_{2}=K_{2} e^{\frac{-E_{2}}{R T_{S}}} c_{N O} C_{N O_{2}} \frac{K_{2}^{\prime} e^{\frac{-E_{2}^{\prime}}{R T_{s}}} c_{N H_{3}}}{1+K_{2}^{\prime} e^{\frac{-E_{2}^{\prime}}{R T_{S}}} c_{N H_{3}}} ; \\
& r_{3}=K_{3} e^{\frac{-E_{3}}{R T_{s}}} C_{N O} \frac{K_{3}^{\prime} e^{\frac{-E_{3}^{\prime}}{R T_{S}}} c_{N H_{3}}}{1+K_{3}^{\prime} e^{\frac{-E_{3}^{\prime}}{R T_{S}}} c_{N_{N}}} ; \\
& r_{4}=K_{4} e^{\frac{-E_{4}}{R T_{S}}} C_{\mathrm{HNCO}} C_{\mathrm{H}_{2} \mathrm{O}} ; \\
& r_{5}=K_{5} e^{\frac{-E_{5}}{R T_{s}}} C_{N_{3}},
\end{aligned}
$$

where $K_{i}$ is pre-exponential factor of the $i$-th reaction; $E_{i}$ is activation energy of the $i$-th reaction, $\mathrm{kJ} / \mathrm{kmol} ; c_{n}$ is molar concentration of the $n$-th component, $\mathrm{kmol} / \mathrm{m}^{3} ; R$ is the universal gas constant, $\mathrm{kJ} /\left(\mathrm{kmol}{ }^{*} \mathrm{~K}\right) ; T_{s}$ is the temperature of the catalyst substrate, $\mathrm{K}$.

Basing on the data from the literature (Winkler et al., 2003; Wurzenberger and Wanker, 2005; Beeckmann and Hegedus, 1991; Schaub et al., 2003; Tang et al., 2008; Riyandwita and Bae, 2011) the values $K$ and $E$ were determined, which are presented in the Table 3. 
Table 3. Values of the pre-exponential factor and activation energy for calculation of reaction rates

\begin{tabular}{cccc}
\hline Pre-exponential factor & Value, unit & Activation energy & Value, $\mathrm{kJ} / \mathrm{kmol}$ \\
\hline $\boldsymbol{K}_{1}$ & $3200 \mathrm{~m} / \mathrm{s}$ & $E_{1}$ & 62571 \\
$\boldsymbol{K}_{1}^{\prime}$ & $1^{*} 10^{-14} \mathrm{~m}^{3} / \mathrm{kmol}$ & $E_{1}^{\prime}$ & -283699 \\
$\boldsymbol{K}_{2}$ & $5^{*} 10^{12} \mathrm{~m}^{4} /\left(\mathrm{kmol}{ }^{*} \mathrm{~s}\right)$ & $E_{2}$ & 72548 \\
$\boldsymbol{K}_{2}^{\prime}$ & $3 * 10^{-16} \mathrm{~m}^{3} / \mathrm{kmol}$ & $E_{2}^{\prime}$ & -293260 \\
$\boldsymbol{K}_{3}$ & $3000 \mathrm{~m} / \mathrm{c}$ & $E_{3}$ & 68391 \\
$\boldsymbol{K}_{3}^{\prime}$ & $1^{*} 10^{-14} \mathrm{~m}^{3} / \mathrm{kmol}$ & $E_{3}^{\prime}$ & -268318 \\
$\boldsymbol{K}_{4}$ & $1^{*} 10^{8} \mathrm{~m}^{4} /\left(\mathrm{kmol} l^{*} \mathrm{~s}\right)$ & $E_{4}$ & 49285 \\
$\boldsymbol{K}_{5}$ & $1000 \mathrm{~m} / \mathrm{s}$ & $E_{5}$ & 80862 \\
\hline
\end{tabular}

Figure 4 shows the calculation results of nitrogen oxide reduction efficiency in exhaust gases in accordance with the above equations (6)-(10), depending on the temperature and composition of the combustible mixture. Increasing the excess air ratio lowers the reduction efficiency (by $8 \ldots 17 \%$ ). The best efficiency is achieved at exhaust gas temperatures of $400 \ldots 500^{\circ} \mathrm{C}$.

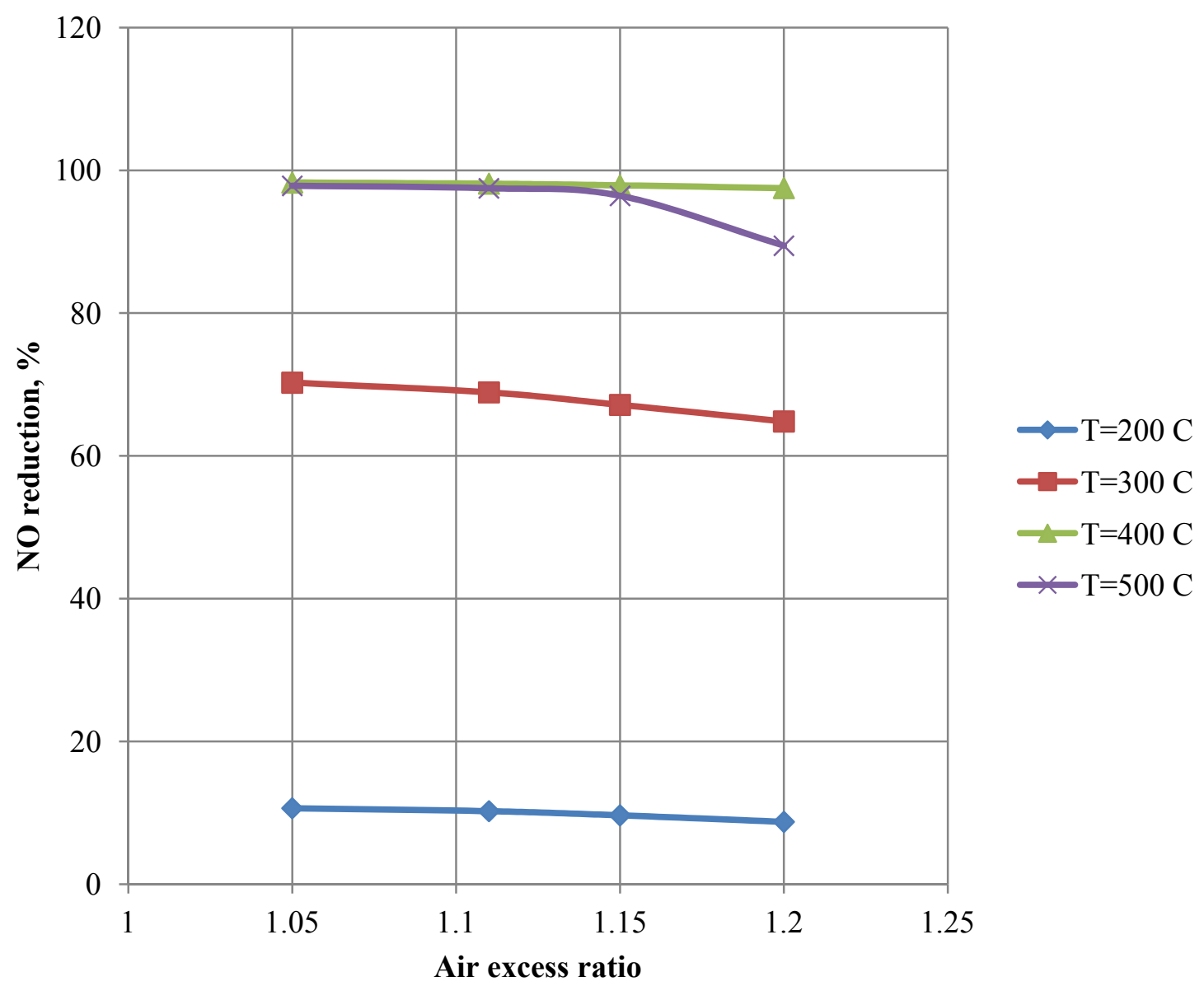

Figure 4. Calculation results of efficiency evaluation of nitrogen oxide reduction in exhaust gases depending on composition of combustion mixture

\section{Conclusions}

Fulfillment of the Euro-5 and Euro-6 environmental requirements is a complex task, which can be accomplished primarily through optimization of gas engine design and operation, its air and fuel supply systems, as well as the use of complex catalytic conversion systems for aftertreatment toxic exhaust conponents.

It is proposed to use for gas engine new combination of three-way catalyst for working on stoichiometric mixtures and selective catalytic reduction system for $\mathrm{NO}_{\mathrm{x}}$ aftertreatment on lean mixtures. 
In order to achieve the requirements on emissions of harmful substances in exhaust gases, when the engine runs with stoichiometric mixture, it is advisable to use a special multifunctional three-way catalyst, specifically designed for complex conversion of exhaust gases produced by a natural gas-powered ICE. A number of catalysts for engine exhaust aftertreatment were identified, which are able to oxidize methane and reduce nitrogen oxides efficiently in a wide temperature range. The key components of three-way catalysts for exhaust gases of natural gas engines are precious metals with $\mathrm{Ce}, \mathrm{Ce}-\mathrm{Zr}$ and other additives to improve efficiency and thermal stability of the contact. Experimental studies have shown that efficient (over 90\%) conversion of gas engine exhaust components takes place in the range of excess air ratio from 0.99 to 1.01 .

Aftertreatment of toxic components of a gas engine with $\lambda>1$ requires the use of catalytic converters, which use a modular design concept allowing to build systems that ensure conversion of nitrogen oxides and methane in the presence of excess oxygen. Such systems combine components with oxidation and reduction functions in accordance with the temperature, concentration and toxic components to oxygen ratio. A good solution to reduce $\mathrm{NO}_{\mathrm{x}}$ emission is an SCR converter using urea. Theoretical studies have shown that the highest efficiency of nitrogen oxides reduction with ammonia is achieved in the temperature range of $400 \ldots 500{ }^{\circ} \mathrm{C}$ and reaches over $97 \%$. This research is performed, a new project with the Ministry of Education and Science of the Russian Federation (the unique identifier for Applied Scientific Research (project) RFMEFI62414X0005).

\section{References}

Bakhmutov, S. V., \& Karpukhin, K. E., (2012). Greencars: the directions of realization and achived results. Scientific magazine of Automotive engineers, 6, 51-54.

Beeckmann, J. W., \& Hegedus, L. L. (1991). Design of monolith catalysts for power plant NOx emission control. Ind. Eng. Chem. Res, 30, 969-978. http://dx.doi.org/ 10.1021/ie00053a020

Caton, J. A., \& Siebers, D. L. (1989). Comparison of nitric oxide removal by cyanuric acid and ammonia. Combust. Sci. And Tech., 65, 277. http://dx.doi.org/10.1080/00102208908924054

Gandhi, S., Graham, G. W., \& McCabe, R. W. (2003). Automotive exhaust catalysis. Journal of Catalysis, 216, 433-442. http://dx.doi.org/10.1016/S0021-9517(02)00067-2

Gélin, P., \& Primet, M. (2002). Complete oxidation of methane at low temperature over noble metal based catalysts: A review. Applied Catalysis B: Environmental, 39, 1-37. http://dx.doi.org/10.1016/S0926-3373(02)00076-0

Gieshoff, J. et al. (2000). Improved SCR Systems for Heavy Duty Applications. SAE technical paper, 2000-01-0189, 12. http://dx.doi.org/ 10.4271/2000-01-0189

Hamill C., Burch, R., Goguet, A., Rooney, D., Driss, H., Petrov, L., \& Daous, M. (2014). Evaluation and mechanistic investigation of a AuPd alloy catalyst for the hydrocarbon selective catalytic reduction (HC-SCR) of NOx. Applied Catalysis B: Environmental, 147, 864-870. http://dx.doi.org/10.1016/j.apcatb.2013.09.047

Jing G., Li, J., Yang, D., \& Hao, J. (2009). Promotional mechanism of tungstation on selective catalytic reduction of NOx by methane over In/WO3/ZrO2. Applied Catalysis B: Environmental, 91, 1-2, 123-134. http://dx.doi.org/10.1016/j.apcatb.2009.05.015

Kašpar, J., Fornasiero, P., \& Hickey, N. (2003). Automotive catalytic converters: current status and some perspectives. Catalysis Today, 77, 419-449. http://dx.doi.org/10.1016/S0920-5861(02)00384-X

Kinnunen, T. (2011). Emission catalyst solutions for Euro 5 and beyond. New Delhi, 48.

Koebel, M., Elsener, M., \& Madia, G. (2001). Recent Advances in the Development of Urea- SCR for Automotive Applications. SAE technical paper, 2001-01-3625, 16. http://dx.doi.org/ 10.4271/2001-01-3625

Komatsu, T., Nunokawa, M., Moon, I. S., Takahara, T., Namba, S., \& Yashima, T. (1994). Kinetic studies of reduction of nitric oxide with ammonia on $\mathrm{Cu}(\sup 2+)$-exchanged zeolites. J. of Catalysis, 148(3), 427-432. http://dx.doi.org/10.1006/jcat.1994.1229

Long, R. Q., \& Yang, R. T. (1999). Selective catalytic reduction of nitrogen oxides by ammonia over Fe3+-exchanged TiO2-pillared clay catalysts. $J$. of Catalysis, 186(2), 254-268. http://dx.doi.org/10.1006/jcat.1999.2558

Luksho, V. A. (2010). Conversion of a diesel engine into a gas-diesel with variable thermodynamic cycle. Alternative Fuel Transport, 6, 4-50.

Luksho, V. A. (2014). Increasing the fuel efficiency of vehicles with gas engines. Proceedings of NAMI, 257, 
124-138.

Luksho, V. A., Kozlov, A. V., \& Terenchenko, A. S. (2011). Performance evaluation of natural gas as a motor fuel in the full life cycle. Alternative Fuel Transport, 3, 4-9.

Nellen, C., \& Boulouchos, K. (2000). Natural Gas Engines for Cogeneration: Highest Efficiency and Near-Zero-Emissions through Turbocharging, EGR and 3-Way Catalytic Converter. SAE technical paper, 2000-01-2825, 12. http://dx.doi.org/ 10.4271/2000-01-2825

Riyandwita, B. W., \& Bae, M. (2011). Three-Dimensional Simulation with Porous Medium as the Washcoat Layer for an SCR Monolith Reactor. SAE technical paper, 2011-01-1240, 14. http://dx.doi.org/ $10.4271 / 2011-01-1240$

Schaub, G., Unruh, D., Wang, J., \& Turek, T. (2003). Kinetic analysis of selective catalytic NOx reduction (SCR) in a catalytic filter. Chemical Engineering and Processing: Process Intensification, 42(5), 365-371. http://dx.doi.org/10.1016/S0255-2701(02)00056-9

Tang, W., Wahiduzzaman, S., Wenzel, S., Leonard, A., \& Morel, T. (2008). Development of a Quasi-Steady Approach Based Simulation Tool for System Level Exhaust Aftertreatment Modeling. SAE technical paper, 2008-01-0866, pp:17. http://dx.doi.org/ 10.4271/2008-01-0866

Uddin, A., Md. Azhar, Komatsu, T., \& Yashima, T. (1995). Selective catalytic reduction of nitric oxide with ammonia on MFI-type ferrisilicate. J. Chem. Soc. Far. Trans, 91, 3275-3282. http://dx.doi.org/ 10.1039/FT9959103275

Weitkamp, J., \& Gläser, R. (2003). Katalyse. Berlin, 74.

Winkler, C., Floerchinger, P., Patil, M. D., Gieshoff, J., Spurk, P., \& Pfeifer, M. (2003). Modeling of SCR DeNOx Catalyst - Looking at the Impact of Substrate Attributes. SAE technical paper, 2003-01-0845, 14. http://dx.doi.org/10.4271/2003-01-0845

Wit, J., Johansen, K., Hansen, P. L., Rossen, H., \& Rasmussen, N. B. (2000). Catalytic emission control with Respect to $\mathrm{CH} 4$ and $\mathrm{CO}$ for highly efficient gas fueled decentralised heat and power production. 5 International Conference on Furnaces and Boilers, 9.

Wurzenberger, J. C., \& Wanker, R. (2005). Multi-Scale SCR Modeling, 1D Kinetic Analysis and 3D System Simulation. SAE technical paper, 2005-01-0948, 18. http://dx.doi.org/ 10.4271/2005-01-0948

\section{Copyrights}

Copyright for this article is retained by the author(s), with first publication rights granted to the journal.

This is an open-access article distributed under the terms and conditions of the Creative Commons Attribution license (http://creativecommons.org/licenses/by/3.0/). 